\title{
Hex open Proximity to terror and post-traumatic stress: a follow-up survey of governmental employees after the 2011 Oslo bombing attack
}

To cite: Hansen MB, Nissen A, Heir T. Proximity to terror and post-traumatic stress: a follow-up survey of governmental employees after the 2011 Oslo bombing attack. BMJ Open 2013;3: e002692. doi:10.1136/ bmjopen-2013-002692

- Prepublication history for this paper is available online. To view these files please visit the journal online (http://dx.doi.org/10.1136/ bmjopen-2013-002692).

Received 6 February 2013 Revised 22 April 2013 Accepted 16 June 2013

Norwegian Centre for Violence and Traumatic Stress Studies, Oslo, Norway

Correspondence to Dr Marianne B Hansen; marianne.hansen@nkvts. unirand.no

\section{ABSTRACT}

Objective: To assess the prevalence of post-traumatic stress disorder (PTSD) symptoms among governmental employees after the 2011 Oslo bombing attack targeted towards the Norwegian Ministries, and to explore the importance of proximity to the bomb explosion as a predictor of PTSD.

Design: A cross-sectional study.

Setting: Data were collected from a survey 10 months after the Oslo bombing on 22 July 2011.

Participants: A total of 3520 employees were invited to the study. Net samples comprised 1927 employees in 14 of the 17 Norwegian Ministries.

Outcome measures: The employees reported where they were at the time of the explosion. PTSD was assessed with the Norwegian version of the PTSD checklist (PCL).

Results: A total of 207 of the $1881(11 \%)$ ministerial employees who completed the survey were present at work when the bomb exploded. Of these, a quarter (24\%, $95 \%$ Cl 18.4 to 30.0 ) had symptom levels equivalent to PTSD, while the prevalence was approximately $4 \%$ among those not present at work. In the latter group the prevalence was similar irrespective of whether their location was in Oslo, other places in Norway or abroad. Leadership responsibility was associated with lower risk for PTSD.

Conclusions: The risk of PTSD is mainly associated with being present at work at the time of a terror attack. For those not present at work, the risk of PTSD is low and independent of proximity to the terror scene. The findings may have implications for planning and priority of healthcare services after a work place terror attack.

Research on employees' mental health in the aftermath of work place directed terror attacks is rare. Available studies of Pentagon staff members after the $9 / 11$ attacks in the USA in 2001 have revealed high prevalence of PTSD among employees who were at work on the day of the attack. ${ }^{12}$ Those injured or exposed to dead bodies had higher rates of psychiatric illness including probable PTSD. ${ }^{1}$ Mental health consequences for employees who were not present at work at the time of

\section{ARTICLE SUMMARY}

Article focus

- Little is known about the impact of work placedirected terror on employees' mental health.

- Previous studies indicate that indirectly exposed individuals are at risk for mental health adversities after terror attacks.

- In this study, we determined the prevalence of post-traumatic stress disorder (PTSD) in groups of employees' exposed to a work place terror attack in relation to where they were at the time of the attack.

Key messages

- After a work place terror attack, the prevalence of PTSD is high among employees who were present at work at the time of the attack.

- For employees who were not at work at the time of the attack, the risk of PTSD is low and independent of proximity to the terror scene.

- After a work place terror attack, psychosocial interventions should primarily be targeted towards employees who were present at work at the time of the attack.

Strengths and limitations of this study

- All employees in the Ministries were included in the study, reducing sample selection bias.

- Moderate response rate (56\%).

the attack were exposed to a lesser extent. ${ }^{3}$ There is some evidence that individuals indirectly exposed to a terror attack through watching mass media may develop PTSD symptoms. ${ }^{4}$ Also, there is some evidence that proximity to a terror scene may increase the risk of PTSD symptoms for individuals not directly exposed. ${ }^{4}$ However, it is not clear whether individuals indirectly exposed to a terror attack should be included in a strategy for screening populations at risk for posttraumatic reactions.

The Oslo bombing in July 2011 was a terror attack on the Government ministries of Norway. A car bomb blast shattered 
governmental buildings, killing eight people and injuring 209 more. Approximately 4000 ministry employees had their office in proximity to the epicentre of the explosion. In the weeks following the terror attack, the governmental occupational health service, with assistance from experienced occupational physicians, offered employees psychological first aid, medical examinations and referrals to specialist health services when required. ${ }^{5}$ High priority was given to ensuring that the needs of the most at-risk individuals were addressed, though how one should define and reach these individuals was subject to discussion. Different selection strategies were proposed, such as proximity to the explosion, degree of exposure or a screening programme for post-traumatic reactions and functioning. The final decision was to include all employees who were at work on the day of the explosion, regardless of which ministry they belonged to.

The aim of the present study was to assess the prevalence of PTSD symptoms among employees 10 months after a terror attack, and more specifically, to what extent proximity to the site of the attack was a predictor of PTSD.

\section{METHODS}

\section{Participants}

The present study is based on data from a survey conducted 10 months after the bomb explosion in Oslo, and comprised employees in 14 of the 17 Norwegian Ministries on 22 July 2011. Based on employees' lists provided by each of the 14 Ministries, a total of 3520 individuals were invited to participate in the study. Each employee received a project-specific identification number generated from their social security number. The key to match these numbers was kept on a unique, off-line server which had access to only one administrative person. Anonymity was secured in that neither the employers nor the researchers had access to this key, and could thus not identify the person behind a response. The procedure was thoroughly explained to the employees before the start of the study.

Of the 3520 invited employees, 1970 responded, giving a response rate of $56 \%$. From this sample, 43 were excluded from the analyses due to missing data, giving a net sample of 1927 employees. Age as well as the proportion of women were higher among responders compared with non-responders, whereas the proportion of employees present at work was similar in the two groups (table 1). In our net sample, $89 \%$ had more than 12 years of education, $73 \%$ were married or cohabiting and $18 \%$ was in a leadership position.

Participants were not identified in order to offer follow-up service to those who met criteria for PTSD. With support from our study, the government occupational health service upheld the initial selection criteria in a second medical follow-up and contacted all employees who had been at work when the bomb exploded. Employees who had not been at work were advised to
Table 1 Age, gender and proportion of employees at work during the 2011 Oslo bombing

\begin{tabular}{|c|c|c|}
\hline & $\begin{array}{l}\text { Responders } \\
(n=1970)\end{array}$ & $\begin{array}{l}\text { Non-responders } \\
(n=1550)\end{array}$ \\
\hline Age, years (SD) & $45.4(10.9)$ & $43.8(11.4)^{*} 19-72$ \\
\hline range & $19-70$ & \\
\hline \multicolumn{3}{|l|}{ Gender, n (\%) } \\
\hline Female & 1133 (57.5) & $760(49.0)^{\star}$ \\
\hline Male & $837(42.5)$ & $790(51.0)^{\star}$ \\
\hline $\begin{array}{l}\text { At work in the } \\
\text { Government area } \\
\text { when the bomb } \\
\text { exploded, } \mathrm{n}(\%)\end{array}$ & 207 (10.5) & $145 †(9.4)$ \\
\hline
\end{tabular}

contact the government occupational health service if they had symptoms affecting daily life functioning and ability to work.

The study was approved by the regional committees for medical and health research ethics.

\section{MEASURES}

A questionnaire was made available online through a web portal established for this purpose. All employees received an invitation letter with a personal code to log on to the web portal and the questionnaire. The code was confidential and only known to the administrative person in charge of data security.

Proximity to the explosion was assessed by asking employees where they were located at the moment when the bomb went off next to the government buildings on the afternoon of 22 July 2011. Respondents were given the following five answer choices: (1) in the government district downtown; (2) in downtown Oslo, but not in the government district; (3) in Oslo, but not downtown; (4) in Norway, but not in Oslo and (5) abroad. There was no significant difference in the distribution of age and gender between these location groups.

To assess PTSD symptoms, the Norwegian version of the PCL, was applied. ${ }^{6}$ The PCL was first introduced in 1993 by Weathers $e t a l^{7}$ and it is now one of the most frequently used self-reported measures on PTSD symptoms. The PCL is a 17-item self-administered questionnaire that assesses the full domain of diagnostic and statistical manual (DSM)-IV PTSD symptoms. ${ }^{8}$ The PTSD diagnosis requires one positive score in cluster $\mathrm{B}$, three in cluster $\mathrm{C}$ and two in cluster $\mathrm{D}$, which is the same number of positive items required in the three clusters in the DSM-IV system. ${ }^{9}$ The same procedure has been shown to perform well for detecting PTSD in the Norwegian population in epidemiological research. ${ }^{6}$

We also assessed the following demographic characteristics: gender, age, educational level, marital status and leadership position. Finally, we asked whether the 
Table 2 Employees of the Norwegian Ministries with PTSD 9-10 months after the 2011 Oslo bombing according to their localisation during the bomb attack

\begin{tabular}{lclc}
\hline & $\mathbf{n}(\%)$ & OR (95\% Cl) & p Value \\
\hline Abroad $(n=357)$ & $13(3.6)$ & ref & - \\
Norway $(n=855)$ & $32(3.7)$ & $1.03(0.5$ to 2.0$)$ & 0.93 \\
Oslo periphery $(n=342)$ & $12(3.5)$ & $0.96(0.4$ to 2.1$)$ & 0.93 \\
Oslo downtown $(n=169)$ & $7(4.1)$ & $1.14(0.4$ to 2.9$)$ & 0.78 \\
Government district $(n=204)$ & $49(24.0)$ & $8.37(4.4$ to 15.9) & $<0.001$ \\
\hline PTSD,post-traumatic stress disorder. & & &
\end{tabular}

participants had witnessed dead people or people dying, whether they had witnessed people seriously injured and whether they had been physically injured themselves.

\section{STATISTICAL ANALYSES}

The association between proximity to the bomb explosion and risk of PTSD was examined using logistic regression. Multiple logistic regression analysis was used to adjust for gender, age, education, marital status and leadership responsibility. We also used logistic regression to examine the association between potentially traumatic experiences and PTSD among those who were present at work in the governmental district when the bomb exploded. All tests were two-tailed and differences were considered significant if $\mathrm{p}<0.05$. The statistical analysis was performed with the software package SPSS V.20.0 for Windows.

\section{RESULTS}

The prevalence of PTSD among the employees of the Norwegian Ministries was highly dependent of whether they were present at work or not when the bomb exploded. Whereas a quarter $(24 \%)$ of the responders who were present at work in the governmental district had PTSD 10 months after the terror attack, the prevalence was around $4 \%$ for employees not present at work, regardless of their proximity to the explosion (table 2).

The difference in risk of PTSD between those present at work and those not present was similar after adjustment for gender, age, education, marital status and leadership position (table 3). Furthermore, there was no association between proximity to the terror attack and risk of PTSD for employees who were not present at work.

Women were twice as likely as men to have PTSD. Furthermore, those with leadership responsibilities and those with more than 16 years of education had less PTSD, whereas age and marital status were not associated with PTSD.

Of the 204 employees who were present at work, 67 $(32.8 \%)$ witnessed dead people or people dying, 132 $(64.7 \%)$ witnessed people seriously injured and 52 $(25.5 \%)$ were physically injured themselves. None of these experiences were significantly associated with PTSD according to unadjusted results (witnessing death $\mathrm{OR}=1.44$, $\mathrm{p}=0.28$; witnessing people seriously injured $\mathrm{OR}=2.05, \mathrm{p}=0.060$; physical injury to self $(\mathrm{OR}=1.82$, $\mathrm{p}=0.092)$ or results adjusted for the other variables $(\mathrm{OR}=1.19, \mathrm{p}=0.63 ; \mathrm{OR}=1.82, \mathrm{p}=0.14 ; \mathrm{OR}=1.65, \mathrm{p}=0.17$; respectively).

Table 3 Probability of PTSD in employees of the Norwegian Ministries, according to localisation during the bomb attack adjusted for gender, age, education, marital status and leadership position

\begin{tabular}{llll}
\hline & OR & 95\% Cl & \\
\hline Location & & & \\
$\quad$ Abroad & ref & 0.49 to 1.95 & - \\
Norway & 0.97 & 0.40 to 2.10 & 0.94 \\
Oslo periphery & 0.92 & 0.42 to 2.92 & 0.83 \\
Oslo downtown & 1.11 & 4.45 to 17.37 & 0.83 \\
$\quad$ Government district & 8.79 & 1.28 to 3.23 & 0.001 \\
Gender (women vs men) & 2.03 & 0.85 to 1.26 & \\
Age (increase of 10 years) & 1.04 & - & \\
Education (years) & & 1.04 to 2.63 & 0.72 \\
$\quad$ More than 16 & ref & 0.80 to 2.92 & 0.03 \\
13-16 & 1.65 & 0.62 to 1.53 \\
12 or less & 1.53 & 0.20 to 0.86 \\
Married or cohabiting (yes vs no) & 0.98 &
\end{tabular}




\section{DISCUSSION}

In this study of employees in the Norwegian ministries 10 months after the 2011 Oslo bombing, the prevalence of PTSD was highly dependent on the employees' localisation when the bomb exploded. While a quarter of those who were present at work in the governmental district had PTSD, the prevalence was around 4\% among those not present at work. In the latter group the prevalence of PTSD was similar irrespective of whether they were in Oslo, other places in Norway or abroad.

The high prevalence of PTSD among employees who were present at work at the time of the explosion is comparable to previous research on work place terror which have shown a prevalence of probable PTSD varying from $14 \%$ to $23 \%$ in individuals directly exposed, assessed 7-36 months after the terror attack. ${ }^{1} \quad 2 \quad 10 \quad 11$ Thus, it seems obvious that direct exposure to the bombing of the Norwegian Ministries had great impact on employees' mental health.

The $4 \%$ prevalence of PTSD in employees not present at work was comparable with estimates of PTSD prevalence in the US general population after the 9/11 terror attacks. ${ }^{4}{ }^{12}$ Research on indirectly exposed individuals after work place terror attacks, that is, employees not present at the time of the incident, is rather scarce. However, the PTSD level is similar to what was found in a Norwegian study of employees not present at work at the time of an industrial disaster. ${ }^{13}$ In our study, it seemed that being an employee at the site of the terror attack was of minor importance for the development of PTSD, compared with the importance of being directly exposed to the bomb explosion.

The bomb explosion could be heard throughout the city, and it generated massive pressure waves and smoke that were noticeable in large parts of Oslo and the surrounding regions. The lack of a relationship between proximity to the bomb explosion and PTSD among those not at work, however, suggests that witnessing the explosion at a certain distance was not related to a higher risk of developing PTSD. These findings are in contrast with findings published after the 9/11 attacks, where it was suggested that the severity of PTSD symptoms was higher among those who were close enough to hear, feel or witness the attack. ${ }^{4}$ However, witnessing the two events at a distance may not be completely comparable as the scenes of the $9 / 11$ attacks were of a larger scale and probably more threatening and terrifying.

Gender differences in the risk for PTSD have yet to be explained. However, the twofold increase in risk for PTSD among women in our study is in line with previous findings in the aftermath of mass violence, ${ }^{14-16}$ as well as after technological and natural disasters ${ }^{17}$ and in the general population exposed to traumatic events. ${ }^{18} 19$ Possible hypotheses include gender differences in how traumatic events are perceived, how men and women react differently to adverse events or how psychological distress is reported differently. ${ }^{20} 21$
We furthermore found that individuals with leadership responsibility had considerable lower risk for developing PTSD compared with non-leaders. This was consistent also after adjustment for education. Leadership responsibilities may increase one's sense of control which in turn may serve as a buffer against stress. ${ }^{22} 23$ Although leadership positions traditionally have been associated with increased stress levels, ${ }^{24}$ it has been demonstrated that leaders have lower levels of anxiety and lower levels of the stress hormone cortisol compared with nonleaders. $^{25}$ Based on our results, we hypothesise that similar mechanisms may contribute to an increased resilience among leaders against developing PTSD.

We did not find any relationship between age and psychological outcome. On this point, the disaster literature differs substantially in that older, middle-aged and younger adults all have been shown to react with more distress after traumatic events, and partly contradictory hypotheses have been formulated. ${ }^{17}$ In our study, all participants were in working age, and the catastrophic event was probably just as unexpected and unfamiliar to all age groups. Also, we found that a higher education level was associated with lower risk of post-traumatic stress, which is in line with many other studies, ${ }^{26}$ including Scandinavian disaster populations. ${ }^{27}$

\section{Methodological considerations}

This study has a number of methodological benefits. All the staff members who were employed in the Ministries at the time of the explosion were asked to participate in our study, reducing sample selection bias. Also, our study sample is probably not confounded by high rates of pre-existing psychopathology or other risk factors for PTSD. In fact, our sample belonged to the working population, had access to a cohesive work environment and had higher than average levels of socioeconomic status and education, which are known protective factors for psychopathology. 262829

Limitations of our study include a moderate response rate of $56 \%$. Thus, we cannot exclude the possibility of sampling bias. For instance, our findings could be biased if affected women or unaffected leaders were more willing to complete the survey. However, we have no theoretical reasons to believe this is the case. More likely, an over-representation of women may have resulted in a slight overestimation of PTSD. Furthermore, the study population consisted of a high proportion of highly educated bureaucrats and government officials and thus, our results may not be applicable to other populations.

The prevalence of PTSD was assessed by the PCL selfreport inventory, which implies that our results must be interpreted with caution. However, the Norwegian version of PCL has been shown to perform well as a diagnostic instrument for detecting PTSD in epidemiological research. ${ }^{6}$ Also, we have not considered fulfilment of the DSM A criteria, but only taken into account the number of symptoms in each symptom cluster. It is likely that the 
stress criterion was not fulfilled for those not at work, and that the prevalence of PTSD secondary to the bomb explosion therefore is overestimated. On the other hand, virtually all employees who were present at work were in a life-threatening situation and a high proportion experienced death or suffering of self or others.

\section{Implications}

When planning psychosocial interventions for the employees after the Oslo bombing, decisionmakers responsible for the allocation of health resources were presented with anecdotal reports about acute stress reactions among employees who had not been present at work. Nevertheless, due to limited resources, a follow-up intervention programme was restricted to those who had been at work. Our findings clearly show that this priority was appropriate. For employees not present at work when the bomb exploded, physical proximity to the terror scene was not associated with increased risk for PTSD. For future psychosocial intervention after work place terror and disasters, priority should be given to those who are present during the event.

Contributors $\mathrm{MBH}$ and $\mathrm{TH}$ conceived, designed and coordinated the study, collected and analysed the data and wrote the paper. AN collected the data and assisted in the analyses and writing of the paper. All the authors approved the final manuscript.

Funding This work was supported by The Norwegian Directorate of Health. Competing interests None.

Ethics approval Regional committees for medical and health research ethics.

Provenance and peer review Not commissioned; externally peer reviewed.

Data sharing statement No additional data are available.

Open Access This is an Open Access article distributed in accordance with the Creative Commons Attribution Non Commercial (CC BY-NC 3.0) license, which permits others to distribute, remix, adapt, build upon this work noncommercially, and license their derivative works on different terms, provided the original work is properly cited and the use is non-commercial. See: http:// creativecommons.org/licenses/by-nc/3.0/

\section{REFERENCES}

1. Grieger TA, Waldrep DA, Lovasz MM, et al. Follow-up of Pentagon employees two years after the terrorist attack of September 11, 2001. Psychiatr Serv 2005;56:1374-8.

2. Grieger TA, Fullerton CS, Ursano RJ. Posttraumatic stress disorder, depression and perceived safety 13 months after September 11. Psychiatr Serv 2004;55:1061-3.

3. Neria Y, Sullivan GM. Understanding the mental health effects of indirect exposure to mass trauma through the media. JAMA 2011;306:1374-5.

4. Schlenger WE, Caddell JM, Ebert L, et al. Psychological reactions to terrorist attacks: findings from the National Study of Americans' reactions to September 11. JAMA 2002;288:581-8.

5. Skogstad M, Skorstad M, Lie A, et al. Work-related post-traumatic stress disorder. Occup Med 2013;63:175-82.
6. Hem C, Hussain A, Wentzel-Larsen T, et al. The Norwegian version of the PTSD Checklist (PCL): construct validity in a community sample of 2004 tsunami survivors. Nord J Psychiatry 2012;66:355-9.

7. Weatherts FW, Litz BT, Herman DS, et al. The PTSD checklist reliability, validity and diagnostic utility. Annual Meeting of the International Society for Traumatic Stress Studies; San Antonio, TX, USA, October 1993

8. Blanchard EB, Jones-Alexander J, Buckley TC, et al. Psychometric properties of the PTSD checklist (PCL). Behav Res Ther 1996;34:669-73.

9. APA. Diagnostic and statistical manual of mental disorders, 4th edition (DSM-IV). WashingtonDC: American Psychiatric Association, 1994.

10. DiGrande L, Neria Y, Brackbill RM, et al. Long-term posttraumatic stress symptoms among 3,271 civilian survivors of the September 11, 2001, terrorist attacks on the World Trade Center. Am J Epidemiol 2011;173:271-81.

11. Grieger TA, Fullerton CS, Ursano RJ. Posttraumatic stress disorder, alcohol use and perceived safety after the terrorist attack on the Pentagon. Psychiatr Serv 2003;54:1380-2.

12. Silver R, Holman EA, Mclntosh DN, et al. Nationwide longitudinal study of psychological responses to September 11. JAMA (Chicago, IL) 2002;288:1235-44.

13. Weisæth L, Eitinger L. Posttraumatic stress phenomena. Common themes across wars, disasters and traumatic events. In: Wilson J, Raphael B, eds. International handbook of traumatic stress syndromes. New York: Plenum Press, 1993:69-77.

14. Galea S, Ahern J, Resnick H, et al. Psychological sequelae of the September 11 terrorist attacks in New York city. $N$ Engl J Med 2002;346:982-7.

15. North CS, Nixon SJ, Shariat S, et al. Psychiatric disorders among survivors of the Oklahoma city bombing. JAMA 1999;282:755-62.

16. Jordan NN, Hoge CW, Tobler SK, et al. Mental health impact of $9 / 11$ Pentagon attack: validation of a rapid assessment tool. Am J Prev Med 2004;26:284-93.

17. Norris FH, Friedman MJ, Watson PJ, et al. 60,000 Disaster victims speak: part I. An empirical review of the empirical literature, 1981-2001. Psychiatry 2002;65:207-39.

18. Breslau N, Davis GC, Andreski $P$, et al. Traumatic events and posttraumatic stress disorder in an urban population of young adults. Arch Gen Psychiatry 1991;48:216.

19. Kessler RC, Sonnega A, Bromet E, et al. Posttraumatic stress disorder in the National Comorbidity Survey. Arch Gen Psychiatry 1995;52:1048.

20. Heir T, Weisæth L. Acute disaster exposure and mental health complaints of Norwegian tsunami survivors six months post disaster. Psychiatry 2008;71:266-76.

21. Olff M, Langeland W, Draijer N, et al. Gender differences in posttraumatic stress disorder. Psychol Bull 2007;133:183-204.

22. Shimazu A, deJonge J, Irimajiri H. Lagged effects of active coping within the demand-control model: a Three-Wave Panel Study among Japanese Employees. Int J Behav Med 2008;15:44-53.

23. Smith P, Frank J, Bondy S, et al. Do changes in job control predict differences in health status? results from a longitudinal National Survey of Canadians. Psychosom Med 2008;70:85-91.

24. Levinson $\mathrm{H}$. When executives burnout. Harv Bus Rev 1981;59:73-81.

25. Sherman GD, Lee JJ, Cuddy AJ, et al. Leadership is associate with lower levels of stress. Proc Natl Acad Sci USA 2012;109:17903-7.

26. Brewin CR, Andrews B, Valentine JD. Meta-analysis of risk factors for posttraumatic stress disorder in trauma-exposed adults. J Consult Clin Psychol 2000;68:748-66.

27. Heir T, Rosendal S, Bergh-Johannesson K, et al. Tsunami-affected Scandinavian tourists: disaster exposure and post-traumatic stress symptoms. Nord J Psychiatry 2011;65:9-15.

28. Stephens $\mathrm{C}$, Long $\mathrm{N}$, Miller I. The impact of trauma and social support on posttraumatic stress disorder: a Study of New Zealand Police Officers. J Crim Justice 1997;25:303-14.

29. Van Der Ploeg E, Kleber RJ. Acute and chronic job stressors among ambulance personnel: predictors of health symptoms. Occup Environ Med 2003;60(Suppl 1):i40-6. 